\title{
A MEMÓRIA, SOB O OLHAR DA NEUROBIOLOGIA E DA NEUROPSICOLOGIA, E SUA RELAÇÃO COM O COMPORTAMENTO ANTISSOCIAL
}

THE MEMORY, UNDER THE VIEW OF NEUROBIOLOGY AND NEUROPSYCHOLOGY, AND ITS RELATIONSHIP WITH ANTISOCIAL BEHA VIOR

\author{
Gabriel J. Chitto Gauer ${ }^{1}$ \\ PUC/RS
}

\section{Resumo}

As pesquisas de Antonio Damásio sobre o sistema nervoso central possibilitaram uma mudança de paradigmas, pois sugerem que as emoções e os sentimentos são indispensáveis para a racionalidade. A agressividade e o comportamento inadequado socialmente são investigados, pois, à luz de uma nova proposição.

Palavras-chave

Comportamento antissocial. Memória. Emoção. Damásio.

\section{Abstract}

Antonio Damásio's research on the central nervous system has enabled a paradigm shift, since it suggests that emotions and feelings are indispensable for rationality. Aggressiveness and socially inappropriate behavior are thus investigated in the light of a new proposition.

Keywords

Socially inappropriate behavior. Memory. Emotion. Damásio.

\section{Considerações iniciais}

${ }^{1}$ Professor do Programa de Pós-graduação em Ciências Criminais, Escola de Direito, PUC/RS. Bolsista Produtividade CNPq. 
A ciência, tradicionalmente, partiu da premissa de que decisões sensatas provêm de pensamentos racionais e de que emoções e razão jamais se misturam. As questões vinculadas à passagem da sensibilidade à racionalidade constitui-se no fundamento do paradoxo moderno cuja dualidade ainda permanece em muitos campos do saber. Lembranças, percepções, emoções e esquecimentos não podem ser explicadas apenas racionalmente, pois são planos diferentes de consciência. Sendo que por muito tempo as discussões a propósito da memória foram baseadas nestas premissas. A perspectiva largamente difundida era de que existiam sistemas neurológicos diferentes para a razão e para a emoção. Como os problemas vinculados à memória dizem respeito tanto as emoções como a razão muitas pesquisas foram e vem sendo realizadas objetivando comprovar diferentes hipóteses.

\section{As pesquisas sobre o Sistema Nervoso Central e as mudanças de paradigmas.}

Entre os pesquisadores que se destacam na área do estudo do Sistema Nervoso Central (SNC), direcionando suas pesquisas para essas questões, Antônio Damásio² se destacou através de estudos realizados em pacientes com uma lesão cerebral específica. O pesquisador, encontrou uma correlação bastante sugestiva de que a emoção era um componente integral da maquinaria da razão.

Ele sugere que certos aspectos do processo da emoção e do sentimento são indispensáveis para a racionalidade. As emoções e os sentimentos, juntamente com a "oculta maquinaria fisiológica" que lhes está subjacente, auxiliam-nos na complexa tarefa de fazer

2DAMÁSIO, Antônio R. O Erro de Descartes: Emoção, Razão e Cérebro Humano. Portugal: Publicações Europa-América, 2000. 
previsões relativamente a um futuro incerto, bem como planejar as nossas ações de acordo com essas previsões. O caso de Phineas Gage, relatado pelo autor, foi marcante para o século XIX, e pela primeira vez se tornou evidente uma ligação entre uma lesão cerebral específica e uma limitação da racionalidade. Com base neste caso, o autor evidencia que lesões do lobo frontal têm sido associadas ao desenvolvimento de comportamento antissocial. Phineas Gage trabalhava na construção de estradas de ferro nos Estados Unidos, em meados do século XIX. Era descrito como uma pessoa equilibrada, meticulosa e persistente quanto aos seus objetivos, além de profissional responsável e habilidoso. Em um acidente durante explosões de rotina para abertura de túneis nas rochas da região, Phineas Gage foi atingido por uma barra de ferro que transfixou seu Crânio, entrando pela face esquerda, abaixo da órbita, e saindo pelo topo da cabeça. Surpreendentemente, ele permaneceu consciente após o acidente, sobreviveu às esperadas infecções no seu ferimento e dois meses após o mesmo, estava recuperado, sem déficits motores e com linguagem e memória preservadas. Ainda que muitas funções estivessem preservadas, a sua personalidade, no entanto, havia se modificado completamente. Phineas Gage transformou-se em uma pessoa impaciente, com baixo limiar à frustração, desrespeitoso com as outras pessoas, incapaz de adequar-se às normas sociais e de planejar o futuro. Daquele momento em diante, não conseguiu estabelecer vínculos afetivos e sociais duradouros ou fixar-se em empregos (Damásio, 1994).

A partir do infortúnio de Phineas Gage, relatos de caso e estudos retrospectivos de veteranos de guerra vêm mostrando a associação entre lesões pré-frontais - mais especificamente lesões nas porções ventromediais do córtex frontal - e a observação clínica de comportamento impulsivo, agressividade, jocosidade e inadequação social. "Psicopatia adquirida" é o termo que tem sido frequentemente 
utilizado para descrever a mudança de personalidade observada em decorrência de danos cerebrais em regiões pré-frontais ${ }^{3}$. Esses dados levaram à sugestão de que um comprometimento do funcionamento do lobo frontal ventromedial poderia contribuir para problemas relacionados ao controle de impulso e personalidade antissocial ${ }^{4}$.

Damásio ${ }^{5}$ sugere que a razão humana está dependente não de um único centro cerebral, mas de vários sistemas cerebrais que funcionam de forma concertada ao longo de muitos níveis de organização neuronal.

Um segundo tema central da obra deste autor é a emoção. A essência de um sentimento, que é o processo de viver uma emoção, não é uma qualidade mental ilusória associada a um objeto, mas sim a percepção direta de uma paisagem específica: a paisagem do corpo. Através de seus estudos com pacientes neurológicos encontrou que a experiência dos sentimentos se encontrava diminuída por lesões no SNC, o que levou o autor a pensar que os sentimentos não são intangíveis nem ilusórios. Ao contrário da opinião científica tradicional, entende-os tão cognitivos como qualquer outra percepção São o resultado de uma curiosa organização fisiológica que transformou o cérebro no público cativo das atividades teatrais do corpo. A emoção e os sentimentos constituem a base daquilo que os seres humanos têm descrito desde há milênios como alma ou espírito humano.

${ }^{3}$ BROWER, M.C.; PRICE, B.H. - Neuropsychiatry of frontal lobe dysfunction in violent and criminal behaviour:a critical review. J Neurol Neurosurg Psychiatry 71(6):720-6, 2001.

${ }^{4}$ DAMÁSIO, Antônio R. O Erro de Descartes: Emoção, Razão e Cérebro Humano. Portugal: Publicações Europa-América, 2000.

${ }^{5}$ DAMÁSIO, Antônio R. O Erro de Descartes: Emoção, Razão e Cérebro Humano, p. 15. 
Um outro ponto a ser considerado é que se para Damásio o que determina que os indivíduos realizem atos antissociais é a dificuldade - por problemas neurológicos - de ligar razão com emoção, para a psicanálise são as precárias vivências infantis onde a agressão está associada ao prazer. Nesta situação o paciente se sente vítima de maustratos e agressão por parte dos mesmos indivíduos que são fonte de prazer, gratificação e sobrevivência. Acreditamos que se faz necessário pensar que tanto problemas neurobiológicos quanto psicológicos estão relacionados a manifestações antissociais. Para além destas afirmativas faz-se necessário referir tantos problemas de conexão entre razão e emoção quanto vivências violentas associadas ao prazer como sendo comprovadamente problemas encontrados em pessoas com vários tipos de transtornos. Há, no entanto, que lembrar que ambas as afirmativas não são excludentes. Podemos encontrar pessoas com transtornos antissociais que apresentem vários problemas.

Uma hipótese que podemos levantar é a de que esta não conexão também se dê devido ao desenvolvimento do mecanismo de cisão - que com certeza envolvem aspectos psico-neurobiológicos. Para preservar o ambiente psíquico da contaminação destas vivências terroríficas precoces se criam mecanismos de desconexão que, como a cardiomegalia, seriam compensatórios, em um primeiro momento, mas acabam por prejudicar o funcionamento psíquico. Neste sentido, um estudo demonstrou que crianças com dois anos de idade que tinham observado abuso doméstico apresentavam sinais de Transtorno de Estresse Pós-Traumático, tais como alterações no padrão de sono, ansiedade excessiva, indiferença emocional e agressividade ${ }^{6}$. Se considerarmos que os principais componentes da personalidade são formados nos primeiros anos de vida, e que as vivências infantis

${ }^{6}$ Niehoff, D. (1999) The Biology of Violence. New York: The Free Press. 
desfavoráveis, mesmo que de pequena intensidade, contribuem para problemas na vida adulta, o que podemos esperar quando nos deparamos com vivências tão deletérias como o espancamento, o abuso sexual e as mais diferentes formas de negligência por parte daqueles de quem a criança depende. Vários estudos demonstram que crianças que foram abusadas e negligenciadas apresentam um risco aumentado de serem presas por um crime violento quando adultas ${ }^{7}$. Tais dados evidenciam como as vivências infantis negativas podem ser prejudiciais tanto a nível neurofisiológico como para o para o funcionamento cerebral. E da mesma forma para as identificações e da formação da personalidade destes indivíduos. Vários estudos indicam que um número razoável de crianças agredidas se tornou adultos agressores. A propósito cabe lembrar observações tão distintas, porém com um conteúdo semelhante, como o mecanismo de identificação com o agressor descrito por Anna Freud, ou a observação por estudiosos do comportamento animal de que macacos que são vítimas de agressão tendem a se tornar agressores.

Uma das abordagens feitas por Damásio, relacionada com as anteriores, é a perspectiva de que o corpo, tal como é representado no cérebro, pode constituir o quadro de referência indispensável para os processos neurais que experenciamos como sendo a mente, ou seja, os nossos mais refinados pensamentos, as mais sensíveis sensações e as nossas melhores ações, as nossas maiores alegrias e as nossas mais profundas mágoas usam o corpo como instrumento de aferição. Porém é importante lembrar que Freud já afirmava que a estruturação do nosso aparelho psíquico dependia e iniciava com a percepção do nosso

\footnotetext{
${ }^{7}$ Windom, C. S. e Maxfield, A. (1996) A prospective examination of risk for violence among abused and neglected children. Annals of the New York Academy of Sciences, v.794, p. 224-237.
} 
corpo e com a diferenciação entre o que sou eu e o que não sou eu. Importante ressaltar que tanto em Freud como em Damásio podemos detectar uma análise que dicotomisa corpo, mente, próprio do paradoxo moderno. A memória está no corpo como um todo. Desde Bergson $^{8}$ que podemos pensar os nossos músculos, nossa pele como roupagens do cérebro. Henri Bergson foi um dos filósofos precursores a dar pistas importantes para que se pudesse pensar o deslocamento do cérebro da caixa craniana para o corpo como um todo, isto ocorreu nos finais do século XIX início do XX.

Damásio afirma que a mente existe dentro de um organismo integrado e para ele, as nossas mentes não seriam o que são se não existisse uma interação entre o corpo e o cérebro. Essa integração ocorreu durante o processo evolutivo, o desenvolvimento individual e o momento atual. Afirma o autor; a mente teve primeiro de se ocupar do corpo, ou nunca teria existido. De acordo com a referência de base que o corpo constantemente lhe fornece, a mente pode então ocuparse de muitas outras coisas, reais e imaginárias. Essa ideia, de acordo com o Damásio9, encontra-se ancorada nas seguintes afirmações: 1) O cérebro humano e o resto do corpo constituem um organismo indissociável, formando um conjunto integrado por meio de circuitos reguladores bioquímicos e neurológicos mutuamente interativos; 2) $\mathrm{O}$ organismo interage com o ambiente como um conjunto, ou seja, a interação não é exclusivamente nem do cérebro, nem do corpo; 3) As operações fisiológicas que denominamos por mente derivam desse conjunto estrutural e funcional e não apenas do cérebro: os fenômenos mentais só podem ser comprometidos no contexto de um organismo

\footnotetext{
${ }^{8}$ BERGSON, Henri (1859-1941). Matéria e Memória. 2a ed. São Paulo: Martins Fontes, 1999.

${ }^{9}$ DAMÁSIO, Antônio R. O Erro de Descartes: Emoção, Razão e Cérebro Humano. Portugal: Publicações Europa-América, 2000. p. 18.
} 
em interação com o ambiente que o rodeia. As vicissitudes da vida influenciam nossa vida psíquica e estas influências alteram nosso funcionamento neurobiológico e do corpo como um todo, como a produção aumentada de glicocorticóides e da atividade do Sistema Nervoso Simpático. Estas alterações podem afetar o funcionamento dos vários sistemas corporais, como o imunológico ${ }^{10}$.

A afirmativa do autor que a mente teve primeiro de se ocupar do corpo, ou nunca teria existido, afirmativa vinculada a uma reflexão sobre a evolução pode ser questionada. Nada garante que ocorreram primeiro funções cerebrais desconectadas do corpo. Bergson ${ }^{11}$ referia no início do século XX, em Matéria e Memória, ao concluir o abismo existente entre o corpo e a mente, fruto do que denominou de dualismo vulgar (dicotomia) entre corpo e espírito que criava um abismo intransponível, percepção e memória física e moral, assim como toda e qualquer dualidade, como duplicatas um do outro. $\mathrm{O}$ autor se coloca, para analisar a memória em uma posição que lhe permitiu tentar ultrapassar o arco hermenêutico entre o real e o ideal.

Damásio, investigando perturbações da memória, da linguagem e do raciocínio em diferentes seres humanos com lesões no SNC. Propõe que ideia de que a atividade mental, dos seus aspectos mais simples aos mais sublimes, requer um SNC e um corpo propriamente dito.

Nesta perspectiva, o amor, o ódio, a bondade, a crueldade, a solução planificada de um problema científico ou a criação de um novo artefato, todos eles têm por base os acontecimentos neurais que ocorrem dentro de um cérebro, desde que este cérebro tenha estado e

\footnotetext{
${ }^{10}$ GAUER, GJC \& RUMJANECK, VD. Psiconeuroimunologia. IN: CATALDO NETO et al. Psiquiatria para Estudantes de Medicina. Porto Alegre: EDIPUCRS, 2003, 944p. ${ }^{11}$ BERGSON, Henri (1859-1941). Matéria e Memória. 2a ed. São Paulo: Martins Fontes, 1999. p. 263-265, 275.
} 
esteja nesse momento a interagir com o seu corpo. A alma respira através do corpo, e o sofrimento, quer comece no corpo ou em uma imagem mental, acontece na carne. Outra perspectiva defendia, por muito tempo foi a de que o cérebro possuía partes especializadas que davam origem a funções mentais distintas. De fato, o debate prolongou-se por mais um século e em certa medida, subsiste até hoje. O fato de que existe uma interação entre mente e corpo e de que a vida mental é indissociável de um SNC íntegro está longe de ser uma ideia nova. Sob este aspecto, Damásio está conduzindo suas pesquisas com base em afirmativas já explicitadas desde o final do século XIX. Entretanto suas reflexões para a questão são relevantes e trazem contribuições para o tema principalmente para o campo da neurologia, tão distanciada dessas reflexões, pois preocupada em desvendar outros mistérios do cérebro, fixou-se em se debruçar sobre o órgão distanciando-se, em sua especialização, do corpo como uma totalidade.

De acordo com o autor, alguns preferem esconder-se atrás da ideia de que tudo está interligado entre si e de que a mente e o comportamento emergem dessa conexão caótica, de uma forma que a neuroanatomia dificilmente revelará. Damásio afirma que estão enganados os que acreditam nessa posição, considerando-se o seguinte: em média, cada neurônio possui cerca de 1.000 sinapses, embora alguns possam ter $5.000 \mathrm{ou} 6.000$. Isso pode parecer um número muito elevado, até consideramos o fato de existirem 10 bilhões de neurônios e mais de 10 trilhões de sinapses. Desta forma, selecionando-se alguns neurônios no córtex cerebral, verificar-se-á que cada neurônio se comunica com um pequeno grupo de outros neurônios, mas nunca com a maioria ou todos os restantes. As principais consequências deste arranjo são as seguintes:

1) O que um neurônio faz depende do conjunto dos outros neurônios vizinhos no qual o primeiro se insere; 
2) O que os sistemas fazem depende de como os conjuntos se influenciam uns aos outros numa arquitetura de conjuntos interligados; e,

3) O contributo de cada um dos conjuntos para o funcionamento do sistema a que pertence depende da sua localização nesse sistema. Vários são os níveis de Arquitetura Neural: neurônios, circuitos locais, núcleos subcorticais, regiões corticais, sistemas e sistemas de sistemas. O SNC é um supersistema de sistemas. Cada sistema é composto por uma complexa interligação de pequenas regiões corticais e núcleos subcorticais, que por sua vez são constituídos por circuitos locais, microscópicos, formados por neurônios, todos eles ligados por sinapses. ${ }^{12}$

Neste sentido Damásio refere que: "a distinção entre doenças do cérebro e da mente, entre problemas neurológicos e psicológicos ou psiquiátricos, constitui uma herança cultural infeliz que penetra na sociedade e na medicina. Reflete uma ignorância básica da relação entre o cérebro e a mente. As doenças do cérebro são vistas como tragédias que assolam as pessoas, as quais não podem ser culpadas pelo seu estado, enquanto que as doenças da mente, especialmente aquelas que afetam a conduta e as emoções, são vistas como inconveniências sociais nas quais os doentes têm muitas responsabilidades"13. Concordamos que os organismos simples, mesmo aqueles com uma única célula e sem cérebro, executam ações de forma espontânea ou em resposta a estímulos do ambiente, isto é, produzem comportamento. À medida que os organismos adquirem maior complexidade, as ações determinadas pelo SNC necessitam de um

\footnotetext{
${ }^{12}$ Sempre que o autor se refere a sistemas, são macroscópicos e os circuitos são microscópicos.

${ }^{13}$ DAMÁSIO, Antônio R. O Erro de Descartes: Emoção, Razão e Cérebro Humano, p. 60
} 
maior processamento. Embora nem todas as ações sejam deliberadas, muitas constituem respostas simples da qual o movimento reflexo é um exemplo: um estímulo produzido por um neurônio que leva outro neurônio a agir. Os grupamentos nervosos podem apresentar muitos passos que intervêm nos circuitos que fazem a mediação entre o estímulo e a resposta e, ainda assim, não possuírem uma mente, caso não satisfaçam uma condição essencial: possuírem a capacidade de exibir imagens internamente e de ordenar essas imagens num processo chamado pensamento. Aqui reside o centro da neurobiologia como concebe o autor: "o processo por meio do qual as representações neurais, que são modificações biológicas criadas por aprendizagem num circuito de neurônios, se transformam em imagens nas nossas mentes; os processos que permitem que modificações microestruturais invisíveis nos circuitos de neurônios (em corpos celulares, dendritos e axônios, e sinapses) se tornem numa representação neural, a qual por sua vez se transforma numa imagem que cada um de nós experiência como sendo sua".

O foco neuropsicológico sobre a memória permite pensar que a redução das emoções pode constituir uma fonte igualmente importante de comportamento irracional. Esta ligação aparentemente ilógica entre ausência de emoções e comportamento anômalo pode ensinar-nos muito sobre a "maquinaria biológica" da razão. Para isso, Damásio recorre à abordagem da neuropsicologia experimental, cuja finalidade é a de explicar a forma como certas operações cognitivas e as suas componentes estão relacionadas com os sistemas neurais e as suas componentes. A neuropsicologia não se ocupa com a descoberta da localização cerebral de um dado sintoma ou síndrome.

A preocupação fundamental foi a de verificar se as observações sobre Elliot se repetiam com outros doentes. Até 1993, Damàsio, 
estudou doze doentes com lesões pré-frontais deste tipo e em todos os casos foi encontrada uma associação entre deficiência na tomada de decisões e perda de emoções e sentimentos. A capacidade da razão e a experiência de emoções estão reduzidas em conjunto, e as suas limitações sobressaem num perfil neuropsicológico em que a atenção, a memória, a inteligência e a linguagem parecem tão intactas que nunca poderiam ser invocadas como explicação das falhas dos doentes na sua capacidade de juízo. Essa diminuição concomitante da razão e dos sentimentos não surge somente após lesões pré-frontais, pode surgir da lesão de outras regiões cerebrais específicas e sugerem uma interação entre os sistemas subjacentes aos processos ditos normais e da razão.

Os comportamentos de certos doentes submetido a leucotomia, (lobotomia frontal) que nunca tinham sido normais, passaram a ser anormais de maneira diferente. A ansiedade extrema deu lugar à calma extrema, as emoções pareciam estagnadas, os doentes pareciam não sofrer, as ideias obsessivas ou delirantes estavam em sossego, a força motriz do doente para responder e agir, por mais "errada" que fosse, estava silenciada. ${ }^{14}$

Salienta o autor, que à época, os doentes com transtornos mentais receberam algum benefício com a cirurgia, pois uma maior

\footnotetext{
${ }^{14} \mathrm{O}$ autor faz referência ao caso de um paciente que sofria de nevralgia do trigêmeo, considerada uma doença intratável e refratária, o que ocasiona uma dor lancinante desencadeada por qualquer toque na pele, o que fazia com que o paciente permanecesse imóvel, todo dobrado na cama em profundo sofrimento. Dois dias após a intervenção cirúrgica o doente estava jogando cartas com um colega de internamento e foi questionado sobre as dores ao que respondeu: "as dores são as mesmas, mas sinto-me bem", ou seja, a operação não tinha afetado a imagem da alteração local da região do corpo servida pelo nervo trigêmeo, mas eliminou a reação emocional que faz parte da dor, terminara o sofrimento, a sua expressão facial, a voz, era de um estado agradável.
} 
deficiência em termos de tomada de decisão talvez fosse mais fácil de suportar do que a ansiedade descontrolada. Por mais inaceitável que seja uma mutilação cirúrgica do cérebro, nos anos 30 o tratamento típico para tais doentes envolvia o seu enclausuramento em instituições mentais e a administração de doses massivas de fármacos com efeito sedativo. Somente no final dos anos 50 que começaram a aparecer os psicofármacos e a revolução que trouxeram para o tratamento das doenças mentais. Estudos recentes evidenciam que estes medicamentos possuem uma função neuroprotetora. Sendo que em longo prazo medicamentos como o Carbonato de Lítio previnem a perda neuronal em pacientes psiquiátricos ${ }^{15}$. Havia, no entanto, uma versão muito mais destrutiva que a leucotomia, era a lobotomia frontal, que provocava lesões extensas e produzia mutilações desnecessárias.

$\mathrm{O}$ raciocínio quanto à tomada de decisões, emoções e sentimentos diminuídos podiam aparecer sozinhos ou como resultado de lesões em outras regiões: setor do hemisfério cerebral direito que contém áreas responsáveis pelo processamento de sinais emitidos pelo corpo, outra região incluía estruturas do sistema límbico, como a amígdala.

Um exemplo, trazido por Damásio foi o caso do juiz do Supremo Tribunal americano, William O. Douglas, que sofreu em 1975 um acidente vascular no hemisfério direito. A ausência de deficiência na linguagem era um bom presságio para o regresso ao seu cargo. Douglas saiu do hospital contra a opinião dos médicos; fazia-se transportar até o Tribunal ou para compras desgastantes e para banquetes. Atribuía sua hospitalização a uma "queda" e repudiava a paralisia do lado esquerdo como um mito. Quando foi forçado a

\footnotetext{
${ }^{15}$ KAPCZINSKI, F; QUEVEDO, J; IZQUIERDO, I. Bases Biológicas dos Transtornos Psiquiátricos. Porto Alegre: ARTMED. 2004.
} 
admitir em uma conferência que não conseguia andar, fugiu da questão dizendo que "andar tem pouco a ver com o trabalho no Tribunal". Ainda assim, convidou os jornalistas para darem um passeio a pé com ele no mês seguinte. Em outra ocasião, perguntado por um visitante como estava sua perna esquerda, disse-lhe que tinha marcado gols de $40 \mathrm{~m}$ de distância com ela e que tinha intenção de assinar contrato com um time de futebol. Além disso, Douglas não observava as convenções sociais com os outros juízes e com os funcionários do Tribunal. Mesmo após ter sido demitido, comportava-se como se não tivesse sido demitido. Desta forma, os anosognósticos possuem além da paralisia uma deficiência no raciocínio e na tomada de decisões, e uma deficiência nas emoções e nos sentimentos.

\section{Considerações conclusivas}

Em suma, parece existir um conjunto de sistemas no cérebro humano consistentemente dedicado ao processo de pensamento orientado para um determinado fim (raciocínio) e à seleção de uma resposta (tomada de decisão) com ênfase especial sobre o domínio pessoal e social. Esse mesmo conjunto de sistemas está também envolvido nas emoções e nos sentimentos e dedica-se em parte ao processamento dos sinais do corpo. Conclui o autor acerca dos sistemas neurais:

1) Estes sistemas encontram-se certamente envolvidos nos processos da razão, ou seja, na planificação e na decisão;

2) um subconjunto destes sistemas está associado aos comportamentos de planificação e de decisão que poderiam ser incluídos na rubrica de pessoais e sociais. Estes sistemas estão relacionados com o aspecto da razão habitualmente designado por racionalidade; 
3) os sistemas identificados desempenham um papel importante no processamento das emoções;

4) os sistemas possuem capacidade suficiente para se poder reter na mente, por um período longo, a imagem de um objeto que já não se encontra presente.

$\mathrm{O}$ autor questiona, "O que permite ao cérebro que os seres humanos se comportem racionalmente? Como funciona?" 16 Em outro momento apresenta os princípios da neurobiologia da racionalidade humana ao nível dos sistemas cerebrais de grande escala, discute as bases neurais do conhecimento, realçando a sua natureza parcelar e a sua dependência de imagens. Também, regressando à história anterior, analisa a regulação biológica e sua expressão nas emoções e nos sentimentos, e dos mecanismos por meio dos quais as emoções e os sentimentos podem ser utilizados na tomada de decisão. O corpo e o cérebro formam um organismo indissociável. $O$ cérebro recebe sinais não apenas do corpo, mas também de partes da sua própria estrutura, as quais recebem sinais do corpo. A parceria cérebro-corpo interage com o ambiente como um conjunto, não sendo a interação só do corpo ou só do cérebro. Porém, os organismos complexos como os humanos, fazem mais do que interagir, mais do que gerar respostas espontâneas ou reativas que no seu conjunto são conhecidas como comportamento. Eles geram respostas internas, algumas das quais constituem imagens (visuais, auditivas, somatosensoriais) que são a base para a mente.

Seria importante pensar na hipótese e não há parceria corpocérebro. O que se pode pensar e que é o comportamento (movimento concreto), capaz de refletir a própria consciência, ou melhor, dizendo,

\footnotetext{
${ }^{16}$ DAMÁSIO, Antônio R. O Erro de Descartes: Emoção, Razão e Cérebro Humano, p. 101.
} 
não há como separar toda e qualquer manifestação do corpo como algo separado da "consciência". Utilizamos o termo consciência na ausência de uma denominação mais adequada. Assim como podemos buscar no passado sensações que experimentamos, que já não estão presentes, e, ao atualizarmos, a experiência podemos colocar em contato passado e presente, acionamos reação contidas no nosso corpo. Diferentemente da lembrança que se constitui em algo que não está presente. Segundo Bergons ${ }^{17}$ "nas amnésias em que todo o período de nossa existência passada, por exemplo, e bruscamente e radicalmente são "arrancados" da memória, não se observa lesão cerebral precisa; e, ao contrário, nos distúrbios de memória em que a localização cerebral é clara e certa, isto é, nas afasias e nas doenças do reconhecimento visual ou auditivo, não são tais situações. A faculdade de evocação que é mais ou menos diminuída em sua vitalidade, como se o paciente tivesse maior ou menor dificuldade de para colocar suas lembranças em contato com o presente. E, portanto, o mecanismo desse contato que deveria ser estudado, a fim de se verificar se o papel do cérebro não seria o de assegurar seu funcionamento, em vez de aprisionar as próprias lembranças em suas células". O autor antecedeu certas questões sobre a atuação do cérebro e, ao mesmo tempo, antecipou o debate sobre o vazio do cérebro.

\section{REFERENNCIAS}

\footnotetext{
${ }^{17}$ BERGSON, Henri (1859-1941). Matéria e Memória. 2a ed. São Paulo: Martins Fontes, 1999. p. 276-277.
} 
BERGSON, Henri. Matéria e Memória. 2a ed. São Paulo: Martins Fontes, 1999.

BROWER, M.C.; PRICE, B.H. - Neuropsychiatry of frontal lobe dysfunction in violent and criminal behaviour:a critical review. J Neurol Neurosurg Psychiatry 71(6):720-6, 2001.

DAMÁSIO, Antônio R. O Erro de Descartes: Emoção, Razão e Cérebro Humano. Portugal: Publicações Europa-América, 2000.

GAUER, G.J.C. \& RUMJANECK, V.D. Psiconeuroimunologia. IN: CATALDO NETO et al. Psiquiatria para Estudantes de Medicina. Porto Alegre: EDIPUCRS, 2003.

KAPCZINSKI, F; QUEVEDO, J; IZQUIERDO, I. Bases Biológicas dos Transtornos Psiquiátricos. Porto Alegre: ARTMED. 2004.

NIEHOFF, D. The Biology of Violence. New York: The Free Press.1999.

WINDOM, C. S. e MAXFIELD, A. A prospective examination of risk for violence among abused and neglected children. Annals of the New York Academy of Sciences, v.794. 1996 